Theso classes correspond roughly to the three stages of a typical complete evaporation curve.

It is hoped that a moro detailed report of this work will shortly bo published.

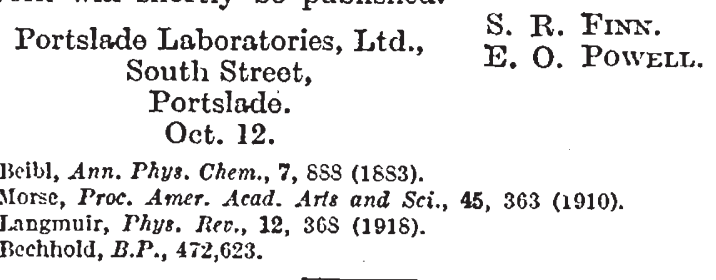

\section{Structure of the Dimeric Forms of o.Isopropenyl- phenols}

o-HYDRoxyisopRopenyL compounds, for oxample (I), readily polymerize to dimoric forms on long intermediate the ring closure, therefore, leads to

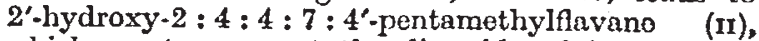
which must represent the dimeride of isopropenyl$m$-cresol.

This structure adequately accounts for the cryptophenolic properties by the presence of the grouping .C(O.) Me.CH, $\mathrm{CHF}_{2}$. in the ortho position to the hydroxyl; the group. $\mathrm{CMe}_{2} \cdot \mathrm{CH}_{2} \cdot \mathrm{CMIO}_{3}$ even para to a phenolic hydroxyl group renders it extremely feebly phenolic. The acid, $2: 4$ : 4 : 7-tetramethylflavane 2 -carboxylic acid (III), would not be expected to undergo further ready oxidation.

The structures of the dimeric forms of other o-hydroxyisopropenyl compounds must be analogous to (II), and there can bo littlo doubt that the dimeric forms of cyclohexenyl-m - and $p$-cresols ${ }^{b}$ are similarly constituted.<smiles>CC(C)(C)C1CCCCC1</smiles>

(I)<smiles>CC1CC2CCCCC2CC1C</smiles>

(I)

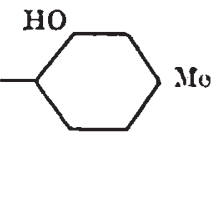

standing or on treatment with hydrogen chloride? These dimerides can be distilled under diminished pressure and aro generally resinous at ordinary tom. perature, but they yield well crystalline monoacetyl derivatives, and contain only one free hydroxyl group. They exhibit only extremely feeble phenolic properties, are saturated, and dopolymerize when distilled under atmospheric pressure. A study of the dimeric form of $i$ sopropenyl-m-cresol (I) ${ }^{2}$ has shown that it yiolds on vigorous oxidation with potassium permanganate a stable carboxylic acid, $\mathrm{C}_{13} \mathrm{H}_{17} \mathrm{O} . \mathrm{CO}_{2} \mathrm{H}$, by degradation of a $m$-cresyl group to a carboxyl group.

Only one very improbable structure has been proposed for these dimerides ${ }^{3}$; this contained an olefinic link, and was based on a formula for a condensation product of $m$-cresol and acetone now known to be incorrects. There appears to bo only ono structuro consistent with the above facts and with theoretical requirements. Solely on valency considerations, there are fourteen monohydric phenols (excluding those containing a 4-membered ring fused to an aromatic nucleus) which could bo produced from two molecules of an o-hydroxyisopropenyl compound such as (I) by the mutual addition of the two isopropenyl groups and ring closure to a saturated cyclic other. Of these structures, four may be rejected on stereochemical grounds as they contain 7 - or 8-membered oxygen rings, and seven because they do not involve the unsymmetrical addition of the two isopropenyl groups, as occurs in the polymerization of styrenes and related compounds; the first step in the condensation is regarded as the formation of a

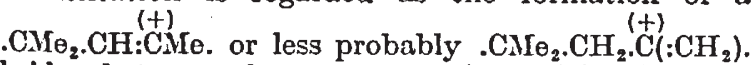
bridge between the two aromatic nucleis. Finally, two of the remaining three possibilities may be eliminated because in ring closure an oxygen atom must unite with the more cationoid of the two unsaturated carbon atoms (marked with $(+)$ ), the doublo bonds being polarized owing to the adjacent phenolic group. In the case of either elsewhere. Soc., 199 (1939). diagram.

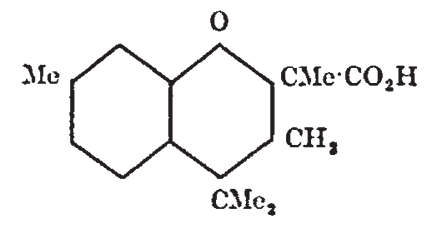

(1II)

A full account of this work will later be published

Dyson Perrins Laboratory,

WILSON BAKER.

D. M. BesLy.

University of Oxford. Oct. 7.

' Fries, K., and Fickewirth, Q., Beriche, 41, 368 (1908); idem. Annalen, 382, 42 (1908) : Fries, K., Gross-Selbeck, W., and Acke, O., Annalen, 402, 306 (1913): Schering-Kahlbaum A.-G., Eng. Pat., 273,684 (1927); Jordan, H., Eng. Pat., 279,856 (1929). There is some doubt as to whether the substances described by G. Guillaumin, Bull. Soc, Chim., [1], 7, 378 (1910), and by J. B. 53, 3390 (1931), as the dimeric form of isopropenyl-m-cresol are really this compound.

'Eng. Pat, 273,684 (1027); Baker, W., and Besly, D. M., J. Chem.

- Jordan, H., Eng. Pat., 270,850 (1929). This structure las been accepted by $F$. Bocttcher, Dissertation, Berlin (1930).

- Baker, W., and Besly, D. M., J. Chem. Soc., 199 (1939).

- Compare structure of a dimeric form of anethole, Goodall, G. D., and Haworth, R. D., J. Chem. Soc., 2182 (1930).

- Bocttcher, F., Dissertation, Berlin (1930).

\title{
Comparing Resistances of Four-Terminal Resistors
}

IN a letter in NATURE of September 30, Mr. Arvon Glynno describes an elegant and simple method for the comparison of four-terminal resistors. In it, as he points out, two of the 'potential' leads have to carry a small current. I would liko to direct attention to another mothod, almost as economical in apparatus, in which no current passes in any of these leads. Resistors of about $1 / 1000 \mathrm{ohm}$ can be compared in this way with an accuracy of ono part per thousand, using apparatus ordinarily available in a laboratory. The principlo will be evident from the accompanying

A low-resistance storage cell $E$ supplies current to the circuit $R, S$; and $R$ is adjusted so as to obtain zero deflection of the galvanometer $G$, first with the resistor $r_{1}$ and then with $r_{2}$ in circuit. If good storage cells aro used in both circuits, steady balances aro 